\title{
ERRATUM
}

\section{A large-signal theory of bunching in the triaxial klystron amplifier-ERRATUM}

ZUMIN QI, JUN ZHANG, HUIHUANG ZHONG, AND ZEHAI ZHANG

(doi:10.1017/S0263034612000572. Published by Cambridge University Press, 25 September 2012)

Equation (13) should be changed into

$$
I(z, t)=I_{I}(z, t)+\sum_{n=1}^{+\infty} I_{I I, n}(z, t) \cdot \cos \left[n \omega\left(t-\left(z-z_{1}\right) / v(\tau)\right)+n \varphi_{0}\right]
$$

That is to say the " $n=-\infty$ " should be changed into " $n=1$ ". 